\title{
Correction to: CDK5 Regulates PD-L1 Expression and Cell Maturation in Dendritic Cells of CRSwNP
}

\author{
C. C. Liu, ${ }^{1}$ H. L. Zhzang, ${ }^{1}$ L. L. Zhi, ${ }^{2}$ P. Jin, ${ }^{1}$ L. Zhao, ${ }^{1}$ T. Li, ${ }^{1}$ X. M. Zhou, ${ }^{1}$ D. S. Sun, ${ }^{3}$ \\ G. H. Cheng, ${ }^{4}$ Q. Xin, ${ }^{4}$ L. Shi, ${ }^{1,5}$ and M. Xia ${ }^{1,5}$
}

Correction to: Inflammation (2018)

https://doi.org/10.1007/s10753-018-0879-3

The article CDK5 Regulates PD-L1 Expression and Cell Maturation in Dendritic Cells of CRSwNP, written by C. C. Liu, H. L. Zhang, L. L. Zhi, P. Jin, L. Zhao, T. Li, X. M. Zhou, D. S. Sun, G. H. Cheng, Q. Xin, L. Shi, and M. Xia was originally published electronically on the publisher's internet portal (currently SpringerLink) on September 06, 2018 with open access. With the author(s)' decision to step back from Open Choice, the copyright of the article changed on September 27, 2018 to (C) Springer Science+Business Media, LLC, part of Springer Nature 2018 and the article is forthwith distributed under the terms of copyright.

The original article has been corrected.

The online version of the original article can be found at https://oi.org/ 10.1007/s10753-018-0879-3

\footnotetext{
${ }^{1}$ Department of Otolaryngology, The Second Hospital of Shandong University, Shandong University, No.274 Beiyuan Road, Jinan, 250033, Shandong Province, China

${ }^{2}$ Department of Otolaryngology, The Central Hospital of Zibo, No.54, Gongqingtuan West Road, Zhangdian District, Zibo, Shandong Province, China

${ }^{3}$ Central Laboratory, The Second Hospital of Shandong University, Shandong University, No.274 Beiyuan Road, Jinan, Shandong Province, China

${ }^{4}$ Department of Cancer Center, The Second Hospital of Shandong University, Shandong University, No.274 Beiyuan Road, Jinan, Shandong, Province, China

${ }^{5}$ To whom correspondence should be addressed at Department of Otolaryngology, The Second Hospital of Shandong University, Shandong University, No.274 Beiyuan Road, Jinan, 250033, Shandong Province, China. E-mails: shili126@sina.com; xiamingsdu@ sohu.com
} 